\title{
Errata
}

May 1999

Volume 103 | Number 9

\section{Ordering of ceramide formation, caspase activation, and mitochondrial changes during CD95- and DNA damage-induced apoptosis}

Annemiek D. Tepper, Evert de Vries, Wim J. van Blitterswijk, and Jannie Borst

\section{J. Clin. Invest. 103:971-978 (1999).}

During the production process, the word caspase was misspelled in the title; the correct title appears above. Also, in the legend for Table 1 the mu symbol $(\mu)$ was formatted incorrectly; the correct legend appears below. We regret the error.

Table 1

Jurkat cells $(J 16)$ were preincubated for $2 \mathrm{~h}$ with zVAD-fmk $(50 \mu \mathrm{M})$, DEVD-CHO $(100 \mu \mathrm{M})$ or left untreated and then exposed to etoposide $(10 \mu \mathrm{g} / \mathrm{ml})$ or IR (30 Gy). After $16 \mathrm{~h}$ incubation, Cer content, nuclear fragmentation, mitochondrial transmembrane potential and cell viability were determined in parallel samples as described in the Methods section. The results are representative of two independent experiments.

\section{Estrogen receptor a mediates the nongenomic activation of endothelial nitric oxide synthase by estrogen}

Zhong Chen, Ivan S. Yuhanna, Zoya Galcheva-Gargova, Richard H. Karas, Michael E. Mendelsohn, and Philip W. Shaul

\section{J. Clin. Invest. 103:401-406 (1999)}

During the production process, panels $a$ and $b$ of Figure 2 were mistakenly repeated as panels $c$ and $d$. The correct display of the figure and accompanying legend is reproduced here. We regret the error and have provided corrected reprints to the corresponding author: Philip W. Shaul, Department of Pediatrics, University of Texas Southwestern Medical Center, 5323 Harry Hines Boulevard, Dallas, Texas 75235-9063, USA. Phone: (214) 648-2015; Fax: (214) 648-2481; E-mail: pshaul@mednet.swmed.edu.
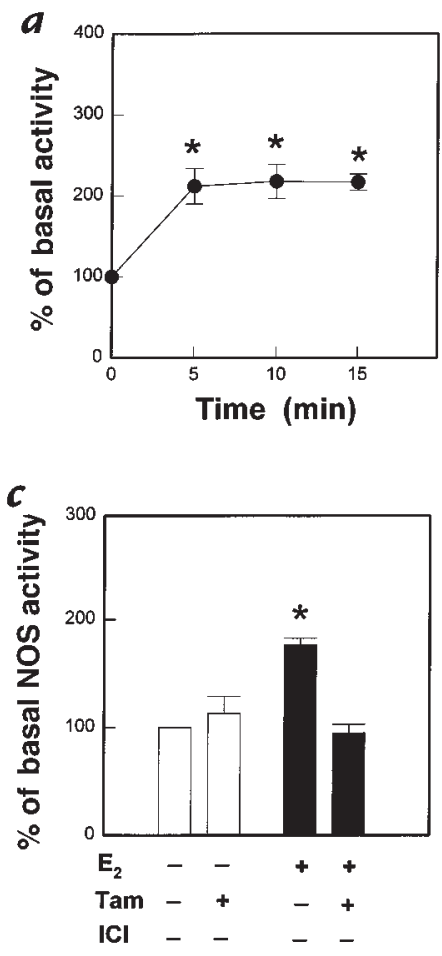

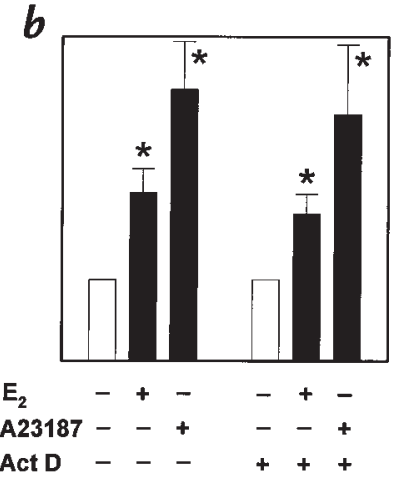

$d$

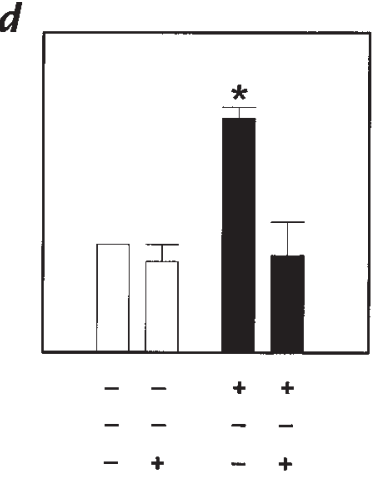

Figure 1

Rapid activation of eNOS in endothelial cells. (a) Effect of $\mathrm{E}_{2}$ on eNOS activity in intact PAEC. $\left[{ }^{3} \mathrm{H}\right] \mathrm{L}$-arginine conversion to $\left[{ }^{3} \mathrm{H}\right] \mathrm{L}$-citrulline was measured over 5-15 min in the presence of $10^{-8} \mathrm{M} \mathrm{E}_{2}$. (b) Effect of actinomycin $\mathrm{D}($ Act $D)$ on the rapid activation of eNOS. After 120 min preincubation in the absence or presence of $25 \mu \mathrm{g} / \mathrm{ml}$ Act $\mathrm{D}, 15$ min incubations were done with or without continued Act $D$ and either $10^{-8} \mathrm{M} \mathrm{E}_{2}$ or the calcium ionophore A23187 $\left(10^{-5} \mathrm{M}\right)$. (c) Effect of tamoxifen on $\mathrm{E}_{2}$-stimulated eNOS activity. Fifteen-minute incubations were performed in the absence or presence of $10^{-8} \mathrm{M} \mathrm{E}_{2}$, with or without $10^{-6} \mathrm{M}$ tamoxifen (Tam) added simultaneously. Partial inhibition (50\%-70\%) was also noted with $10^{-8} \mathrm{M} \mathrm{Tam}$ (13). (d) Effect of ICl 182,780 on $\mathrm{E}_{2}$-stimulated eNOS activity. Fifteen-minute incubations were performed in the absence or presence of $10^{-8} \mathrm{M} \mathrm{E}_{2}$, with or without $10^{-5} \mathrm{M} \mathrm{ICl} 182,780$ added simultaneously. Full inhibition was also observed with $10^{-6} \mathrm{M} \mathrm{ICl} 182,780$ (13). Values are mean \pm SEM; $n=4-6 .{ }^{*} P<0.05$ vs. basal. $E_{2}$, estradiol-17 $\beta$; eNOS, endothelial nitric oxide; $P A E C$, pulmonary artery endothelial cells. 